\title{
Soft-Stall Control versus Furling Control for Small Wind Turbine Power Regulation
}

\author{
E. Muljadi \\ T. Forsyth \\ C.P. Butterfield \\ National Wind Technology Center \\ National Renewable Energy Laboratory
}

Presented at

Windpower '98

Bakersfield, CA

April 27-May 1, 1998

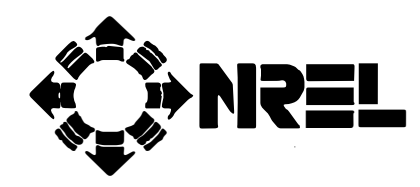

National Renewable Energy Laboratory 1617 Cole Boulevard

Golden, Colorado 80401-3393

A national laboratory of the U.S. Department of Energy Managed by Midwest Research Institute for the U.S. Department of Energy under contract No. DE-AC36-83CH10093

Work performed under task number WE803020

July 1998 


\section{NOTICE}

This report was prepared as an account of work sponsored by an agency of the United States government. Neither the United States government nor any agency thereof, nor any of their employees, makes any warranty, express or implied, or assumes any legal liability or responsibility for the accuracy, completeness, or usefulness of any information, apparatus, product, or process disclosed, or represents that its use would not infringe privately owned rights. Reference herein to any specific commercial product, process, or service by trade name, trademark, manufacturer, or otherwise does not necessarily constitute or imply its endorsement, recommendation, or favoring by the United States government or any agency thereof. The views and opinions of authors expressed herein do not necessarily state or reflect those of the United States government or any agency thereof.

Available to DOE and DOE contractors from:

Office of Scientific and Technical Information (OSTI)

P.O. Box 62

Oak Ridge, TN 37831

Prices available by calling (423) 576-8401

Available to the public from:

National Technical Information Service (NTIS)

U.S. Department of Commerce

5285 Port Royal Road

Springfield, VA 22161

(703) 487-4650 


\title{
SOFT-STALL CONTROL VERSUS FURLING CONTROL FOR SMALL WIND TURBINE POWER REGULATION
}

\author{
E. Muljadi \\ T. Forsyth \\ C.P. Butterfield \\ National Renewable Energy Laboratory \\ National Wind Technology Center \\ 1617 Cole Boulevard \\ Golden, CO 80401
}

\begin{abstract}
Many small wind turbines are designed to furl (turn) in high winds to regulate power and provide overspeed protection. Furling control results in poor energy capture at high wind speeds. This paper proposes an altemative control strategy for small wind turbines - the soft-stall control method.

The furling and soft-stall control strategies are compared using steady state analysis and dynamic simulation analysis. The soft-stall method is found to offer several advantages: increased energy production at high wind speeds, energy production which tracks the maximum power coefficient at low to medium wind speeds, reduced furling noise, and reduced thrust.
\end{abstract}

\section{INTRODUCTION}

Many small wind turbines use an upwind rotor configuration with a tail vane for passive yaw control. Typically, the tail vane is hinged, allowing the rotor to furl (turn) in high winds, providing both power regulation and over-speed protection. Most of today's small wind turbines are operated using a variable speed generator. At higher wind speeds, the generated power of the wind turbine can go above the limit of the generator or the wind turbine design. When this occurs, small wind turbines use mechanical control or furling to turn the rotor out of the wind resulting in shedding the aerodynamic power or a steep drop in the power curve. Often, small turbine rotors furl abruptly at a wind speed only slightly above their rated wind speed, resulting in a very "peaky" power curve and poor energy capture at higher wind speeds. This energy loss is compounded by the furling hysteresis, in which the wind speed must drop considerably below the rated wind speed before the rotor will unfurl and resume efficient operation.

One way to improve the performance of furling wind turbines is to design the rotor to furl progressively, causing the power output to remain at or near rated power as the wind speed increases beyond rated. This approach has two drawbacks: wind turbine rotors operating at high furl angles tend to be very noisy and experience high flap loads.

This paper proposes an altemative control strategy - the soft-stall control method - for use with small wind turbines. The soft-stall concept is to control the generator rotations per minute (rpm) and achieve optimum operation over a wide range of rotor $\mathrm{rpm}$. In controlling the generator rpm, the soft-stall concept regulates the stall mode of the wind turbine, thus furling can be delayed in normal operation. Furling is still used in the soft-stall concept during very high winds and emergency conditions.

The objective of this paper is to investigate an analytical comparison between furling (mechanical control) and soft stall (electrical control) for small wind turbines. Potential advantages of soft-stall control are listed as follows: 
- Delays furling as long as possible, which increases energy production

- Controls the wind turbine rotational speed to achieve the maximum power coefficient

- Operates the wind turbine at a low tip-speed ratio during high wind speeds to reduce noise and thrust loads.

The approach taken to investigate this objective is to use steady-state and dynamic analyses. The steadystate analysis is performed to examine the operation and boundaries of operation for the wind turbine. The dynamic analysis is performed to investigate the interaction between the electrical (soft stall) control and the mechanical (furling) control and to observe the dynamic behavior of the wind turbine.

To compare the furling and the soft-stall method, a battery charging wind turbine system is chosen. Two systems of battery charging are compared. One is battery charging with the furling mechanism and the other is battery charging with the soft-stall mechanism. Figure 1 shows two different configurations of the system we investigated. In Figure 1a, battery charging without load control is shown. This system consists of a permanent magnet synchronous generator and a three phase diode rectifier. The electrical characteristics (power versus RPM) cannot be changed once the voltage, the generator, and the wind turbine are chosen. In Figure 1b, the soft-stall system with load control is shown. The only difference between Figure 1a and Figure $1 \mathrm{~b}$ is the addition of the DC-DC converter that allows the power to be controlled. With the DC-DC converter between the rectifier and the battery bank within the range of the generator limit the power entering the battery can be controlled according to any prescribed power versus rpm schedule. The DC-DC converter and the battery bank as a whole can be viewed as a variable voltage battery bank. The resistive load and the switch are used to divert the generated power when the battery bank is fully charged to avoid gassing during overcharging.

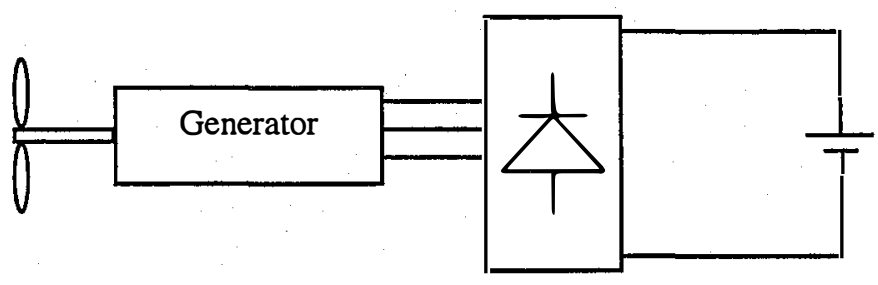

(a) Without Load Control

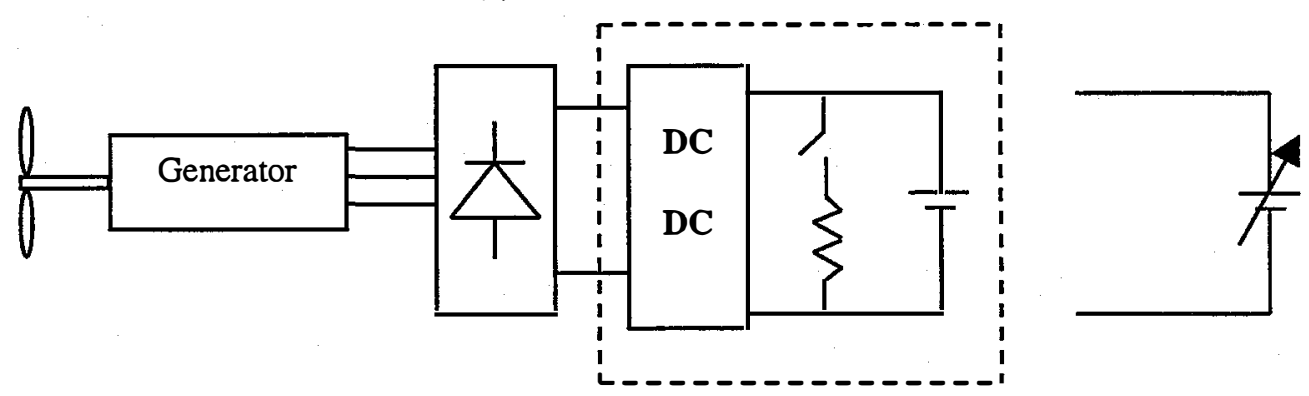

(b) With Load Control

FIGURE 1. TWO DIFFERENT BATTERY CHARGING SYSTEMS 
There are many references available for modeling permanent magnet generators [1-3] and the derivations of the generator equations will not be described in this paper. Similarly, the aerodynamic models of the wind turbine can be found in many references [4-6] and the detailed model and equations will not be covered in this paper. Soft stall control can also be applied to utility size wind turbines to limit the power and rpm [7].

This paper is divided into five sections. The first section introduces the two different control methods investigated in this paper. The second section describes the basic characteristics of a wind turbine. The third section describes the steady state analysis. The fourth section discusses the results of the dynamic simulation analysis. And, finally the overall summary of the paper is presented in the fifth section.

\section{BASIC CHARACTERISTICS OF THE WIND TURBINE}

The wind turbine to be considered is operated in normal mode during low to medium wind speeds. However, in high wind speeds the wind turbine output must be limited. The furling control can be considered to have two parts to the $\mathrm{C}_{\mathrm{p}}$ curve; one part is during normal operation and the other is during furling operations. Furling is shown as a drop off in power production followed by a slow linear increase in power (see Figure 5).

The basic equation of the wind turbine aerodynamic power can be written below:

$$
P_{\text {aero }}=0.5 \rho \text { A C } \mathrm{p}(\mathrm{TSR}) \mathrm{V}^{3}
$$

Equation 1

where:

$\mathrm{P}_{\text {aero }} \quad=$ aerodynamic power generated by the wind turbine

$\rho=$ specific density of the air $(\mathrm{kg} / \mathrm{m} 3)$

A $\quad=$ swept area of the blades

$\mathrm{Cp}(\mathrm{TSR})=$ power coefficient of the wind turbine as a function of tip speed ratio

$\mathrm{TSR}=$ tip speed ratio $(\omega \mathrm{R} / \mathrm{V})$

$\omega \quad=$ rotor speed $(\mathrm{rad} / \mathrm{sec})$

$\mathrm{V} \quad=$ wind speed $(\mathrm{m} / \mathrm{sec})$

$\mathrm{R} \quad=\operatorname{rotor} \operatorname{radius}(\mathrm{m})$

Thus the wind turbine, as the prime mover of the generator, has an output that depends on the wind speed and rpm. The tip-speed ratio (TSR) is the rotational velocity of the wind turbine rotor divided by the wind speed. At any wind speed, the aerodynamic power is dependent on the rpm of the generator. In the normal wind speed region, the operation of the wind turbine is controlled to produce a maximum $C_{p}$ condition at which the generated power is instantaneously controlled to follow the equation:

$P_{\text {gen }}=0.5 \rho C_{\text {ptarget }} A\left(R / T S R_{\text {target }}\right)^{3} \omega^{3}$

Equation 2

where all the parameters above are known except the rotor speed rpm. The above equation is simplified as a cube function of the rotor speed. Since the generator power is directly related to the rpm cubed, when the available aerodynamic power decreases, the generator load is higher than the available aerodynamic power resulting in a slower rotor speed. As the rotor speed slows down, the power of the generator will also be reduced as the cube of the rpm decreases.

In Figure 2, the thrust coefficient $\left(C_{t}\right)$ and the power coefficient $\left(C_{P}\right)$ are drawn on the same scale as a function of TSR. Note that the thrust continuously increases as the TSR increases. It is shown that the 


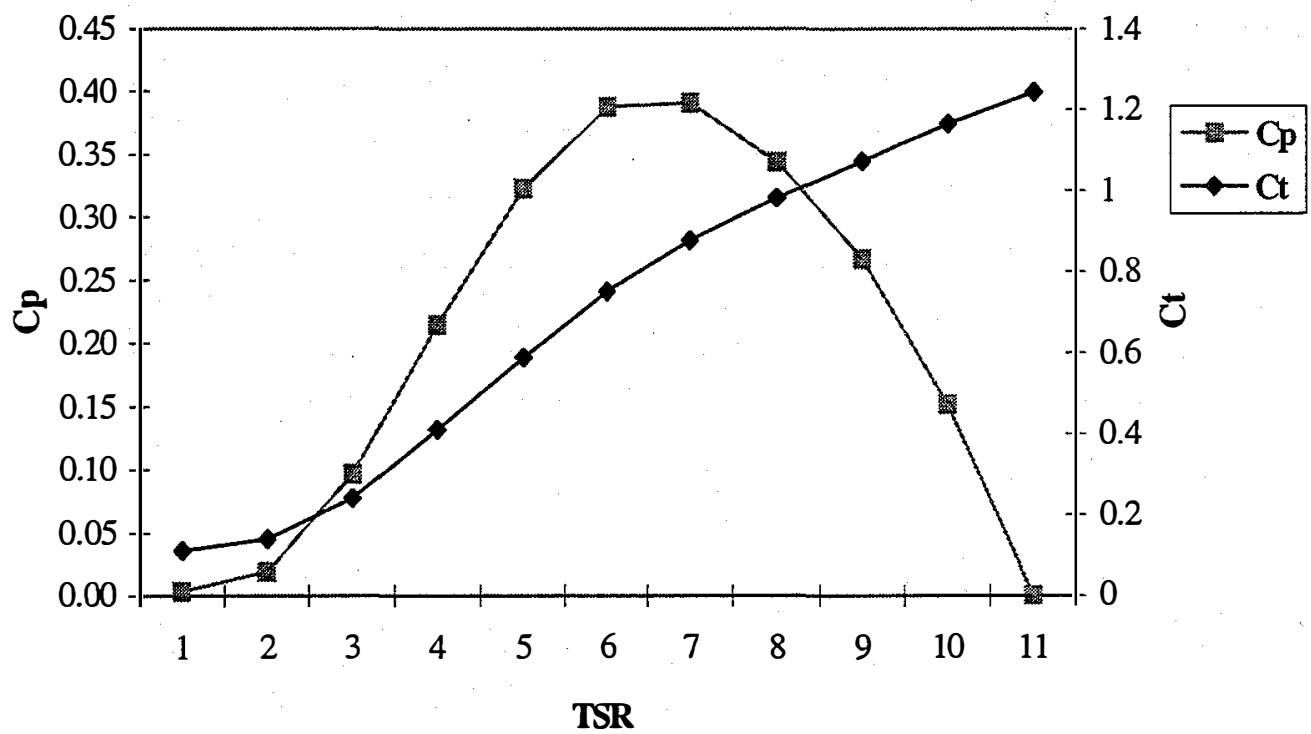

FIGURE 2. POWER COEFFICIENT AND COEFFICIENT OF THRUST AS A FUNCTION OF TIP-SPEED RATIO

power coefficient reaches maximum value $\left(\mathrm{Cp}_{\max }=0.4\right)$ at a TSR $\left(\mathrm{TSR}_{\text {target }}\right)$ of 6.5 while the coefficient of thrust continues to increase. It is intended that the wind turbine be operated about $\mathrm{TSR}_{\text {target }}$ in the low to medium wind speed thus maintaining $\mathrm{Cp}_{\max }$ values most of the time.

Figure 3 is the free body diagram of the system. It illustrates the simplified description of the furling mechanism. In a normal condition, the effective wind speed $\mathrm{V}_{\mathrm{n}}=\mathrm{V}$ is the useful wind directed to the plane of rotation. The thrust is the force perpendicular to the plane of rotation. It is proportional to the square of the effective wind speed. The in-plane force, $\mathrm{P}_{\text {force, }}$, which is parallel to the plane of rotation, does not exist in the normal condition. When the wind speed increases, both the thrust and the $\mathrm{P}_{\text {force }}$ on the blade create moments due to the offset $\mathrm{d} 1$ and $\mathrm{d} 2$. As a result, the angle $\theta$ increases thus reducing the normal component of the wind speed $\mathrm{V}_{\mathrm{n}}$. As $\mathrm{V}_{\mathrm{n}}$ decreases, the thrust and the wind energy converted to aerodynamic power also decreases.
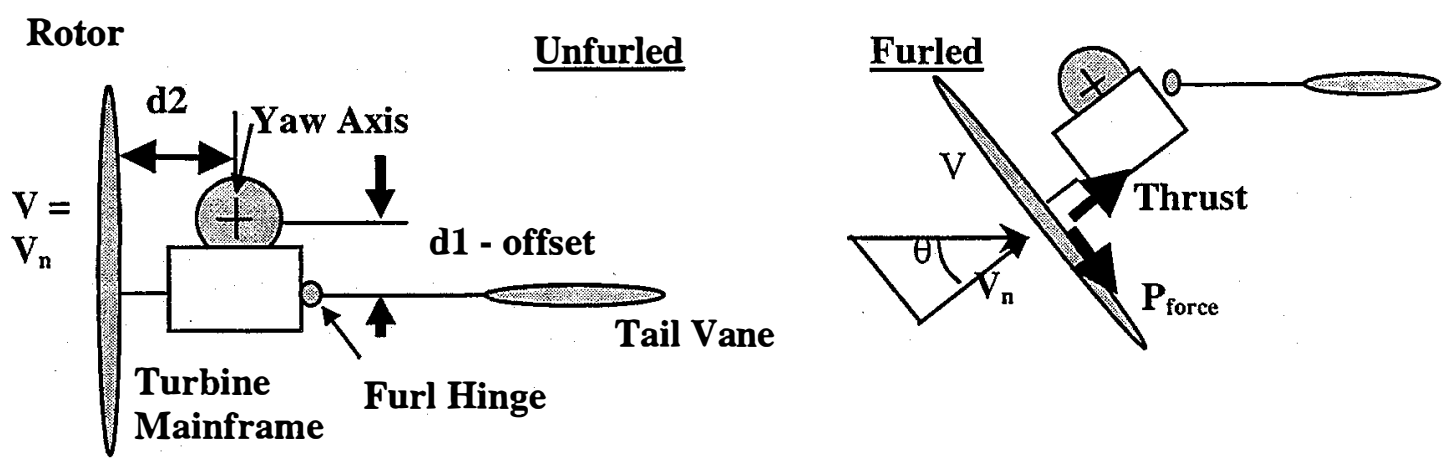

(a) Normal Condition

(b) Furling Condition

FIGURE 3. FREE BODY DIAGRAM OF THE FURLING MECHANISM 
The forces contributing to the moment around the pivot point are the thrust and the $\mathrm{P}_{\text {force. }}$. The thrust can be computed by considering the normal component of the wind speed.

Thrust $=0.5 \rho \mathrm{C}_{\mathrm{t}} \mathrm{A} \mathrm{V}_{\mathrm{n}}{ }^{2}$

Equation 3

The furling moment created by the blade can be written as

$M_{B}=$ Thrust $d_{1}+P_{\text {force }} d_{2}$

Equation 4

And the restraining moment from the tail vane can be approximately represented by

$\mathrm{M}_{\mathrm{T}}=\mathrm{K}_{1}+\mathrm{K}_{2} \theta$

Equation 5

where $\mathrm{K} 1$ and $\mathrm{K} 2$ are the parameters of the wind turbine for the furling mechanism.

The equilibrium is governed by the following equation:

$\mathrm{M}_{\mathrm{B}}-\mathrm{M}_{\mathrm{T}}=\mathrm{J} \theta^{\prime \prime}$

Equation 6

where $\mathrm{J}$ is the moment inertia of the turbine with respect to the yaw axis, $\theta$ is the furling angle, and $\theta$ " is the acceleration of furling rotation.

In Figure 4, the moment contributions from $\mathrm{M}_{\mathrm{B}}$ and $\mathrm{M}_{\mathrm{T}}$ are shown on the same graph for a specified offset $\mathrm{d} 1$ and $\mathrm{d} 2$. The moments are computed at a constant TSR for simple illustration. It is shown that when the wind speed is low $(10 \mathrm{~m} / \mathrm{s})$, the $M_{B}$ is lower than the $M_{T}$ thus the furling angle is at its minimum and furling is not initiated. When the wind speed increases to $16 \mathrm{~m} / \mathrm{s}$, the furling moment at zero furling angle is lower than the restraining moment, thus furling is not initiated. However, at $20 \mathrm{~m} / \mathrm{s}$, the furling moment is always higher than the restraining moment at any furling angle resulting in the

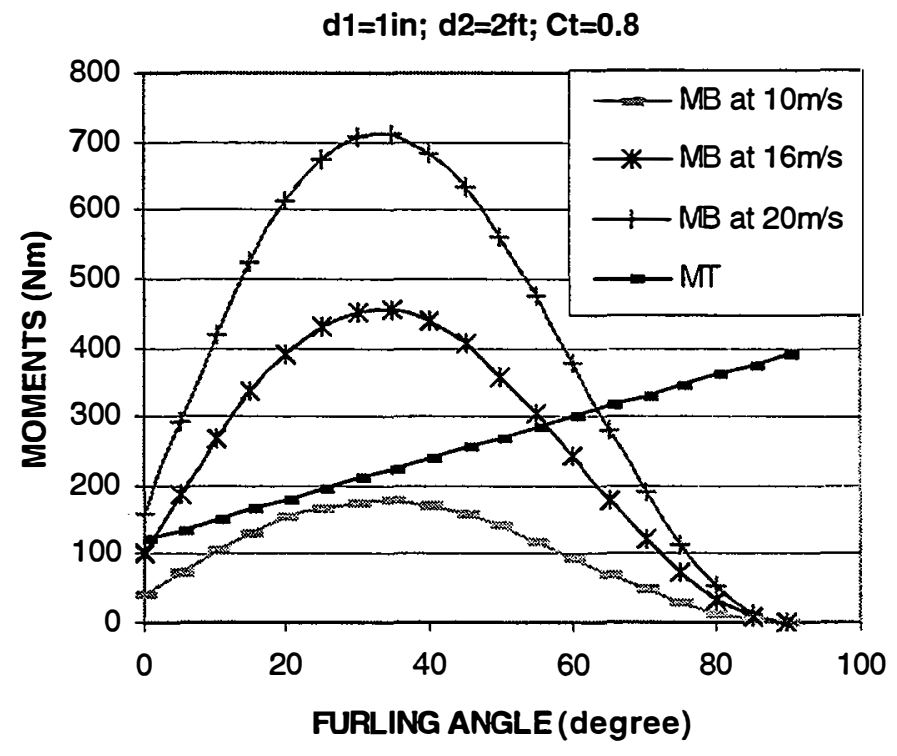

FIGURE 4. MOMENTS AFFECTING THE FURLING MECHANISM VERSUS FURLING ANGLE 
initiation of furling up to approximately 65 degrees. Similarly, the same process can be used to explain the returning furling angle to zero angle when the wind speed decreases.

Note that manufactured wind turbines use a damper to reduce the furling loop hysteresis. Damping is necessary to keep the wind turbine from cycling or chattering in and out of furling. The damping plus the gyroscopic effect of turning wind turbine blades add to the unproductive time of entering and leaving the furling condition creating a hysteresis during transition. All of these delays reduce the wind turbine energy production.

\section{STEADY STATE ANALYSIS}

The steady state analysis was computed using a package program called Mathcad. The battery charging system is controlled by two different methods. Both systems consist of a wind turbine connected to a three-phase permanent magnet generator. The output of the generator is connected to a three-phase bridge diode rectifier to charge a battery. In the conventional system, the output of the rectifier is directly connected to a battery bank. Thus the conventional system does not have any controller to change the load profile. Once the generator, battery voltage, and wind turbine are selected, the power versus rpm characteristics cannot be altered. The soft-stall system is modified from the conventional system by adding a DC-DC converter between the output of the diode bridge and the terminal input of the battery bank. Thus the soft-stall system is capable of changing the load profile characteristic of the generator. Both the soft-stall and the conventional system are equipped to furl at high wind speed or loss of load. In the soft-stall method, the furling process is delayed to a much higher wind speed.

In the furling method, the wind turbine generator is operated between cut-in wind speed and cut-out wind speed. In Figure 5 and 6, the thick line represents the conventional method of furling and the thin line represents the method of soft-stall control. For the furling method, it is assumed that the output is directly connected to a battery set via a rectifier. The generator can start charging the battery above a certain rpm. Below this rpm, the generator does not produce enough voltage to charge the battery. There is no optimization technique used to control the charging process and the wind turbine is operated in a

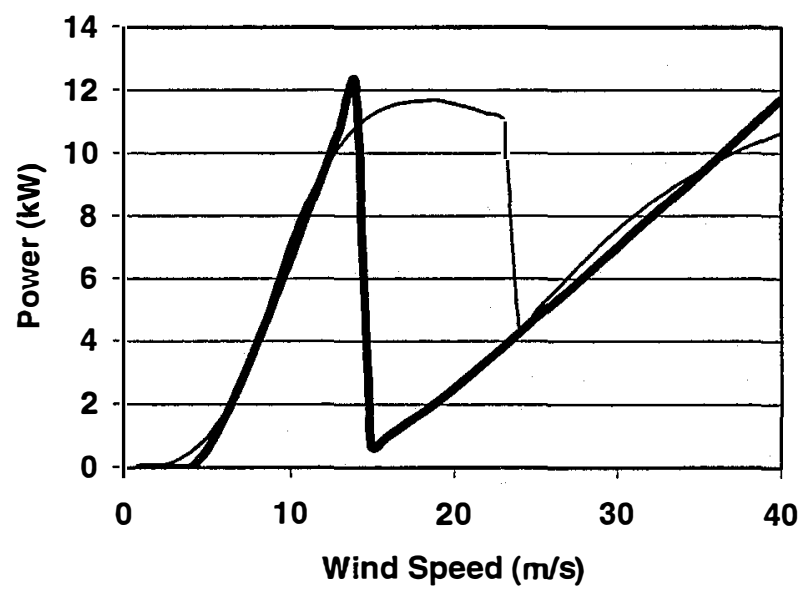

(a) Generator Power

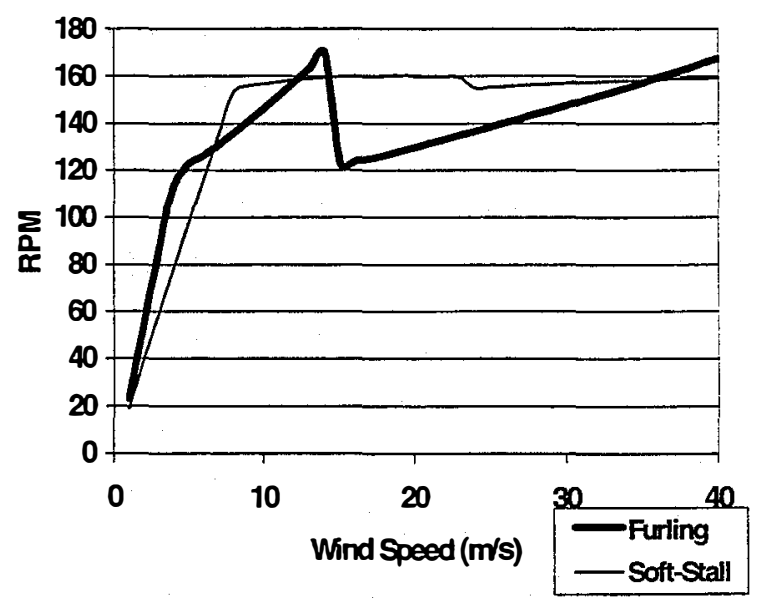

(b) Rotor RPM

FIGURE 5. GENERATED POWER AND ROTOR RPM FOR FURLING AND SOFT STALL CONTROL 


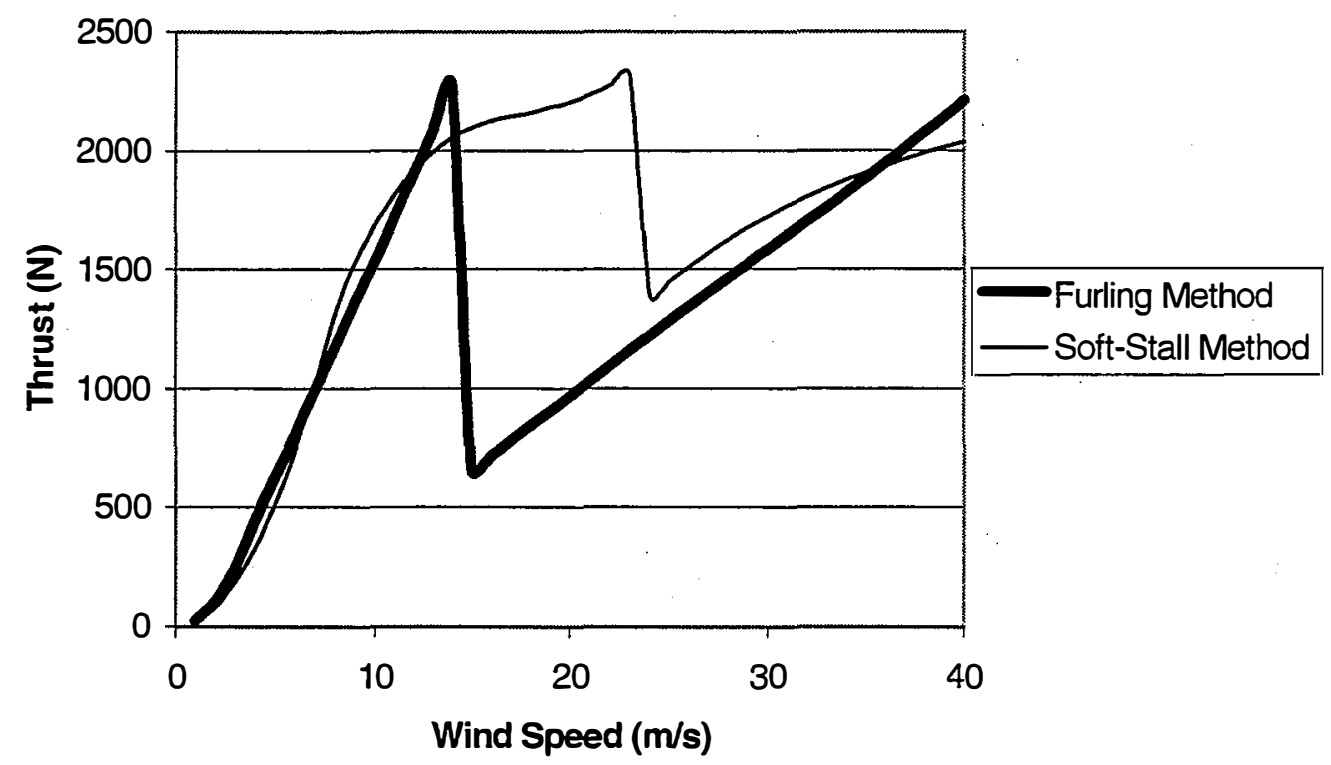

FIGURE 6. THRUST LOAD VERSUS WIND SPEED

non-optimal mode or the $C_{p}$ operation does not reach the maximum $C_{p}$ possible. The generator parameters and the chosen battery voltage can affect the output capability of the wind turbine. As the wind speed increases, the rpm and power increase. However, the rotor rpm versus wind speed is not controllable. The generator starts generating above a certain rpm, i.e., when the generated voltage is higher than the battery voltage.

As shown in Figure 6, the thrust also increases as the wind speed increases. When the furling moment surpasses the restraining moment, furling is initiated. This furling mechanism is initiated at a lower wind speed (approximately $14 \mathrm{~m} / \mathrm{s}$ ) than the soft-stall method (approximately $25 \mathrm{~m} / \mathrm{s}$ ).

In the soft-stall method, the output of the generator is connected to the battery via a power converter, which enables a match between the battery voltage and the generator voltage for any rpm. A cut-in power can be selected to ensure that the wind power will be operated only if the turbine can generate enough power to cover the losses of the wind turbine. As shown in Figure 5, as the wind speed increases, the rpm also increases. To operate the wind turbine at maximum $\mathrm{C}_{\mathrm{p}}$, the generator needs to be controlled to use a certain load profile for power versus RPM. This load profile is generated from equation 2 and requires the knowledge of wind turbine parameters such as $\mathrm{Cp}_{\max }$, TSR for $\mathrm{Cp}_{\max }$, wind turbine swept area, and the air density of the turbine site.

Note that the soft-stall method generates slightly more power than the furling method in the low to medium (0-14 m/s) wind speed due to $C \mathrm{p}_{\max }$ operation. By operating at constant $\mathrm{Cp}_{\max }$, the TSR is also constant. In Figure 5b, the constant TSR operation is shown by a linear relationship between rotor rpm and wind speed. For higher wind speeds, the soft-stall method generates more power than the furling method because the wind turbine is forced to stall instead of furling. In the soft-stall mode the rotor is 
loaded to slow down the rotor rpm thus the operating TSR decreases. The thrust load as is shown in Figure 6 also decreases due to low TSR operation. The soft-stall method illustrates furling initiated at a higher wind speed (about $25 \mathrm{~m} / \mathrm{sec}$ ) versus the furling method (approximately $14 \mathrm{~m} / \mathrm{s}$ ). As a consequence of delayed furling in the soft-stall method, the wind turbine still generates power between. $14 \mathrm{~m} / \mathrm{sec}$ to 25 $\mathrm{m} / \mathrm{sec}$. In comparison for the same range of wind speed, the furling method generates substantially less power than the soft-stall method due to earlier furling. The delayed furling has several advantages such as an increase in energy production for higher wind speeds and a reduced number of furling occurrences, which can reduce the fatigue loads on the wind turbine.

\section{DYNAMIC SIMULATION ANALYSIS}

The dynamic analysis is based on a chosen wind speed site and the parameters of the wind turbine including the generator. The dynamic analysis is computed using a package program called Advanced Continuous Simulation Language (ACSL). Figure 2 shows the PROP93 output of the wind turbine power coefficient, $C_{p}$ and thrust coefficient, $C_{t}$ as a function of TSR. A mechanical damper is included in this dynamic analysis to avoid a chattering effect (in which the wind turbine goes in and out of furling mode) and the furling angle is limited between 0 degrees and 70 degrees.
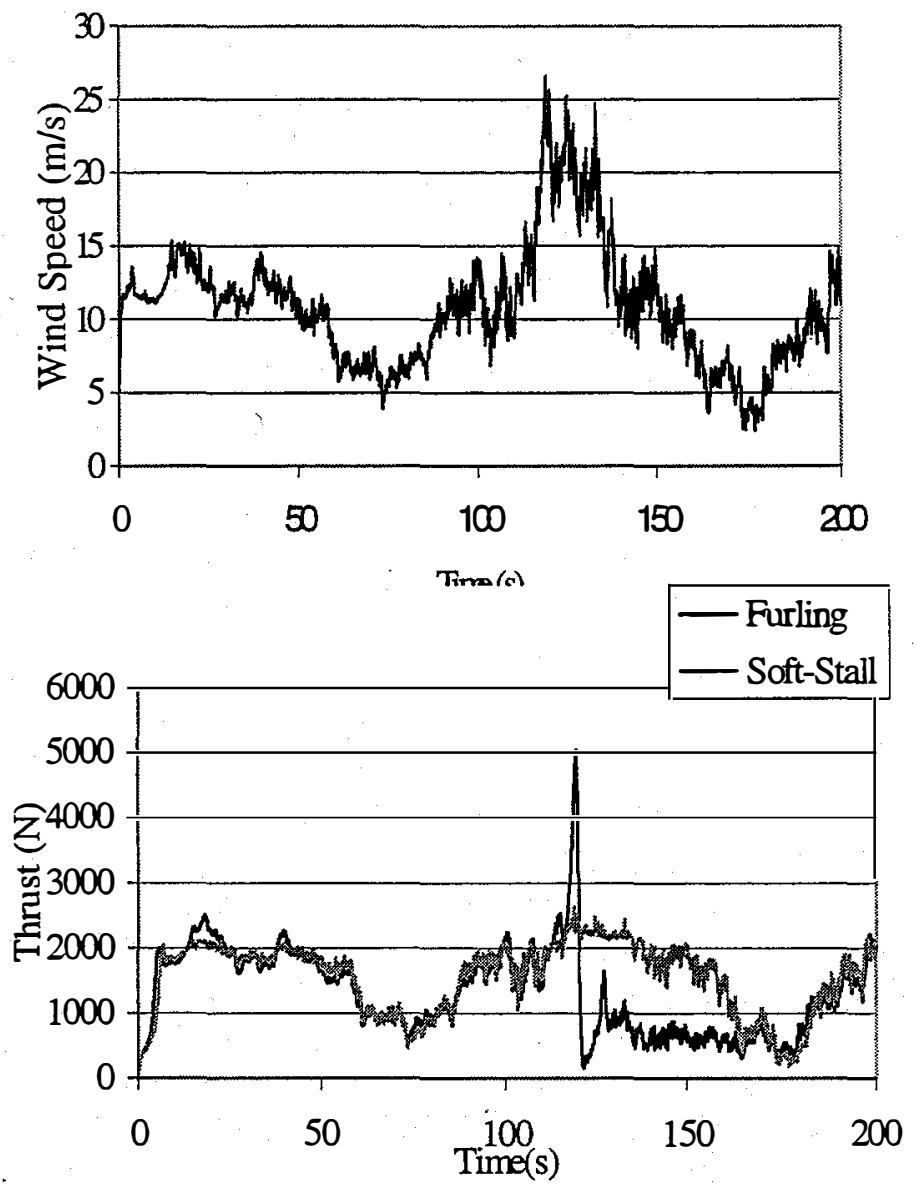

FIGURE 7. WIND SPEED AND THRUST LOAD 
As described in the previous sections, the furling method does not have active control to adjust the generator power versus rpm while the soft stall method has the capability to control the generator power versus rpm. This control capability is shown in Figure 7 and 8. In Figure 7, the results of wind speed and thrust versus time are shown. It is shown that the thrust load of the furling method reaches the limit (2300 Newton) at a lower wind speed $(14 \mathrm{~m} / \mathrm{s})$ than the soft stall method. The thrust varies as a function of the $C_{t}$ and the square of the wind speed. Since the thrust coefficient is a function of tip speed ratio, it can be managed by controlling the tip speed ratio or the rotor RPM.
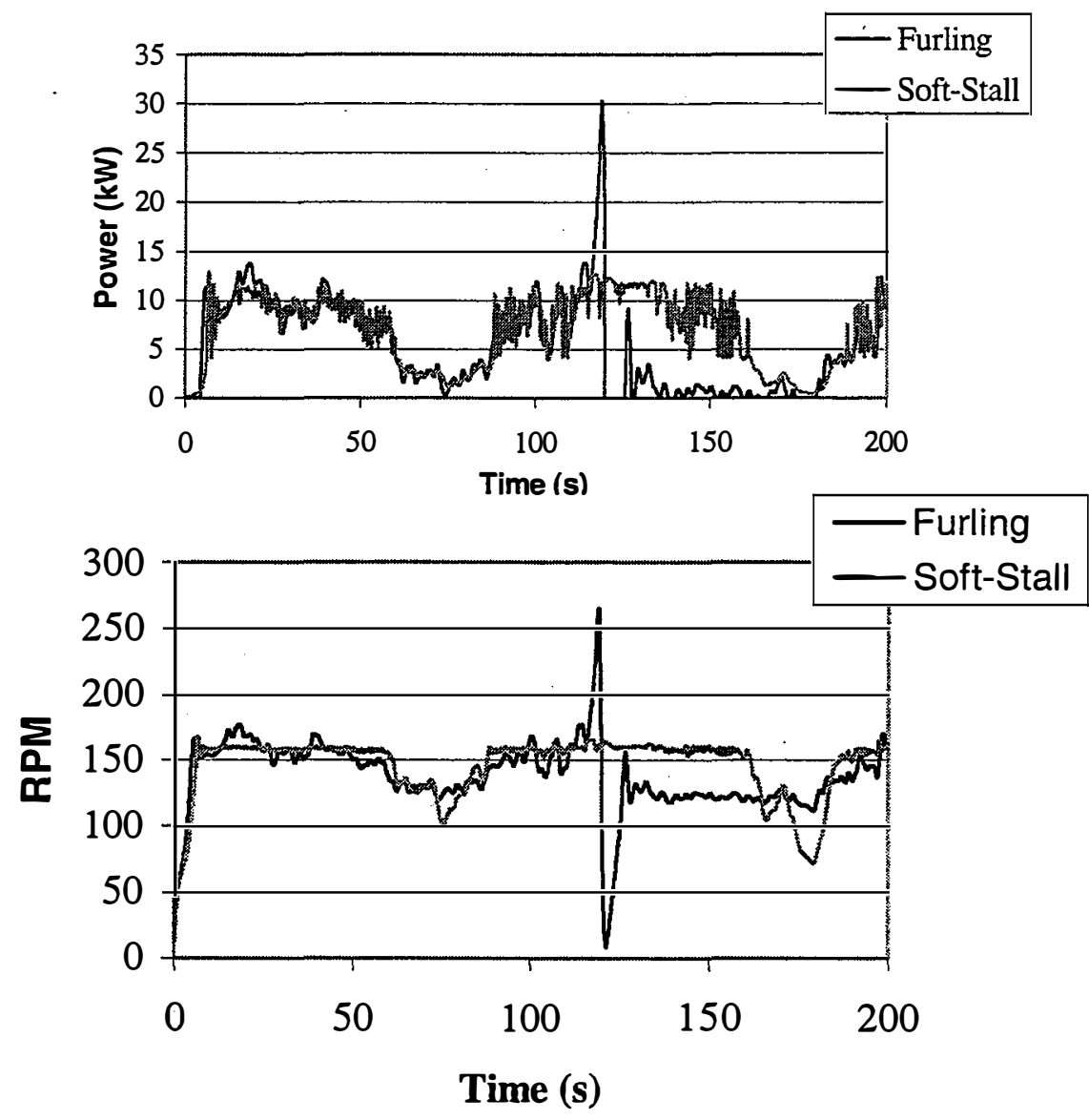

FIGURE 8. GENERATOR POWER AND ROTOR RPM

In Figure 8, the generator power and the rotor rpm are shown for both the furling method and the softstall method. For the soft-stall method, the generator is controlled to maintain constant $\mathrm{Cp}\left(\mathrm{at} \mathrm{Cp}_{\max }\right)$ in the low to medium wind speeds and in the high wind speed region the generator is controlled to generate more power thus slowing down the rotor rpm or lowering the TSR. Also shown in Figure 8, between 100 seconds to 120 seconds, the rotor speed is kept almost constant for the soft stall mode. During the same period, the furling method shows the rpm increasing dramatically due to lack of power control. The generator power is proportional to the cube of the rotor rpm, thus by stalling the wind turbine in the softstall method, the rotor rpm is controllable and the generator power is also controllable. For this dynamic analysis, the soft-stall method doesn't furl while the furling method furls at approximately $14 \mathrm{~m} / \mathrm{s}$ wind 
speed. Note that between $t=120 \mathrm{~s}$ and $\mathrm{t}=180 \mathrm{~s}$, there is minimal energy production for the furling method. On the other hand, the soft-stall method continuously generates power.

\section{CONCLUSION}

The use of two different control strategies was investigated analytically for small furling wind turbines. In comparing the furling method and the soft-stall method, we find that the soft-stall method offers the following advantages over the furling method:

- $\quad$ Energy production at higher wind speeds is increased by controlling the tip speed ratio, thus allowing the turbine to delay furling.

- $\quad$ Energy production for low to medium wind speeds is increased by controlling the generator to track the maximum power coefficient.

Furling noise is reduced due to the decrease in frequency of furling and decrease in average TSR.

- $\quad$ Thrust is reduced in high wind speed due to operation in TSR.

\section{ACKNOWLEDGEMENTS}

We wish to thank Neil Kelley for providing the wind data sets used in this work. We wish to acknowledge our management at NREL and the U.S. Department of Energy (DOE) for encouraging us and approving the time and tools we needed for this project. DOE supported this work under contract number DE-AC36-83CH10093.

\section{REFERENCES}

1 Ong, C.M., Dynamic Simulation of Electric Machinery. Prentice Hall, 1998.

2 Kraus, P.C.; Thomas, C.J. "Simulation of Symmetrical Induction Machinery." IEEE Trans. On

Power Apparatus and Systems, Vol. PAS 84, No. 11, Nov, 1965, pp. 1038-1053.

3 Muljadi, E.; Drouilhet, S.; Holz, R.; Gevorgian, V. "Analysis of Wind Power for Battery Charging." Presented at ASME Conference, Houston, Texas, Jan 28-Feb 2, 1996.

4 Eggleston, D.M.; Stoddard, F.S. Wind Turbine Engineering Design. New York, NY: Van Nostrand Reinhold, 1987.

5 Johnson, G.L., Wind.Energy Systems. Englewood Cliffs, NJ: Prentice Hall, 1985.

6 Drouilhet, S.; Muljadi, E.; Holz, R.; Gevorgian, V. "Optimizing Small Wind Turbine Performance in Battery Charging Applications." Presented at Windpower 95 Conference, Washington, DC, March 27-30, 1995.

7 Muljadi, E.; Pierce, K.; Migliore, P. "Control Strategy for Variable-Speed, Stall-Regulated Wind Turbines." Presented at the $17^{\text {th }}$ American Controls Conference (ACC), Philadelphia, PA, June 2426, 1998. 